\title{
Outbreaks of Tilapia Lake Virus Infection, Thailand, 2015-2016
}

\section{Win Surachetpong, Taveesak Janetanakit, Nutthawan Nonthabenjawan, Puntanat Tattiyapong, Kwanrawee Sirikanchana, Alongkorn Amonsin}

\author{
Author affiliations:, Kasetsart University, Bangkok, Thailand \\ (W. Surachetpong, P. Tattiyapong); Chulalongkorn University, \\ Bangkok (T. Janetanakit, N. Nonthabenjawan, A. Amonsin); \\ Chulabhorn Research Institute, Bangkok (K. Sirikanchana); \\ Ministry of Education, Bangkok (K. Sirikanchana)
}

DOI: https://dx.doi.org/10.3201/eid2306.161278

During 2015-2016, several outbreaks of tilapia lake virus infection occurred among tilapia in Thailand. Phylogenetic analysis showed that the virus from Thailand grouped with a tilapia virus (family Orthomyxoviridae) from Israel. This emerging virus is a threat to tilapia aquaculture in Asia and worldwide.

$\mathrm{V}$ iral diseases are common causes of illness and death in cultured fish; such viruses include infectious salmon anemia virus, infectious hematopoietic necrosis virus, and viral hemorrhagic septicemia virus (1). With regard to tilapia, some viral pathogens, including betanodavirus, iridovirus, and herpes-like virus $(2,3)$, reportedly cause severe disease. In recent years, Thailand has experienced extensive losses of tilapia; most losses occurred 1 month after transfer of fish from hatchery to grow-out cages in public rivers or reservoirs (1-month mortality syndrome). During routine investigation of this syndrome, multiple bacterial and parasitic infections were identified. However, no association was established between the outbreaks and any primary causative agent(s). Most deaths occurred within 2 weeks after the first dead fish were found. Similar observations of extensive losses of raised tilapia and wild fish in Israel and Ecuador have been reported $(4,5)$. These outbreaks led to identification of a virus affecting tilapia, called tilapia lake virus (TiLV). The epidemiologic pattern and clinical signs for infected fish in Thailand led to suspicion of an illness of unknown etiology that was similar to TiLV infection.

During 2015-2016, we investigated 32 outbreaks involving a large number of deaths of unknown cause among Nile tilapia (Oreochromis niloticus) and red hybrid tilapia (Oreochromis spp.). The outbreaks occurred at fish farms in central, western, eastern, and northeastern Thailand (online Technical Appendix Figure 1, https://wwwnc.cdc.gov/EID/article/23/6/16-1278Techapp1.pdf). Affected fish were commonly found within 1 month after transfer from the hatchery facility to growout ponds or cages. In general, clinical signs and high mortality rates were associated with fish weighing 1-50 g (online Technical Appendix Figure 2). Mortality rates among tilapia farms were $20 \%-90 \%$; higher rates were associated with secondary bacterial and parasitic infections. Mortality rates peaked within 14 days after the first dead fish were found.

As part of the outbreak investigation, samples of brain tissue were taken from fish at each of the 32 outbreak locations (each with a mortality rate $>1 \%$ /day for 3 consecutive days): 10-30 moribund fish and 5-10 apparently healthy fish from the same culture areas. In total, 325 samples were collected and tested for etiologic agent(s) $(4,6)$. Samples from fish involved in 22 of the 32 outbreaks were positive for TiLV (online Technical Appendix Table 1).

For our study, we selected a field sample positive for TiLV (designated TiLV/Tilapia/Thai/TV1/2016) and processed it for whole-genome sequencing. Another 6 TiLVs were selected for sequencing of the putative polymerase basic 1 (PB1) gene (online Technical Appendix Table 2). TiLV genome sequencing was conducted by using newly designed primers based on reference TiLVs available in the GenBank database (7). Nucleotide sequences of 7 TiLVs from Thailand were submitted to GenBank (accession nos. KX631921-36).

Comparison of the TiLVs from Thailand with those from Israel showed high nucleotide and amino acid identities (95.18\%-99.10\%). Among TiLVs from Thailand, nucleotide and amino acid identities for segment 1 or the putative PB1 gene of the virus were high $(99.61 \%-100 \%)$ (online Technical Appendix Table 3). Genetic analysis of the putative PB1 protein of TiLVs from Thailand and the viruses of the family Orthomyxoviridae showed that TiLVs from Thailand possessed motifs preA, A, B, C, D, and E similar to those of Orthomyxoviridae viruses, including influenza $\mathrm{A}, \mathrm{B}$, and $\mathrm{C}$ viruses; infectious salmon anemia virus; Dhori virus; and Thogoto virus (online Technical Appendix Table 4) (8-10). Phylogenetic analysis showed that TiLVs from Thailand were closely related to TiLVs from Israel and grouped with the viruses of the family Orthomyxoviridae but not Arenaviridae and Bunyaviridae (Figure). This result suggests that the genetic composition of this emerging virus was similar to that of orthomyxoviruses and homologous with previously published TiLV sequences.

Our PCR and whole-genome findings demonstrate genetic homology between TiLV from Thailand and the etiologic agent of a novel RNA virus infection of 


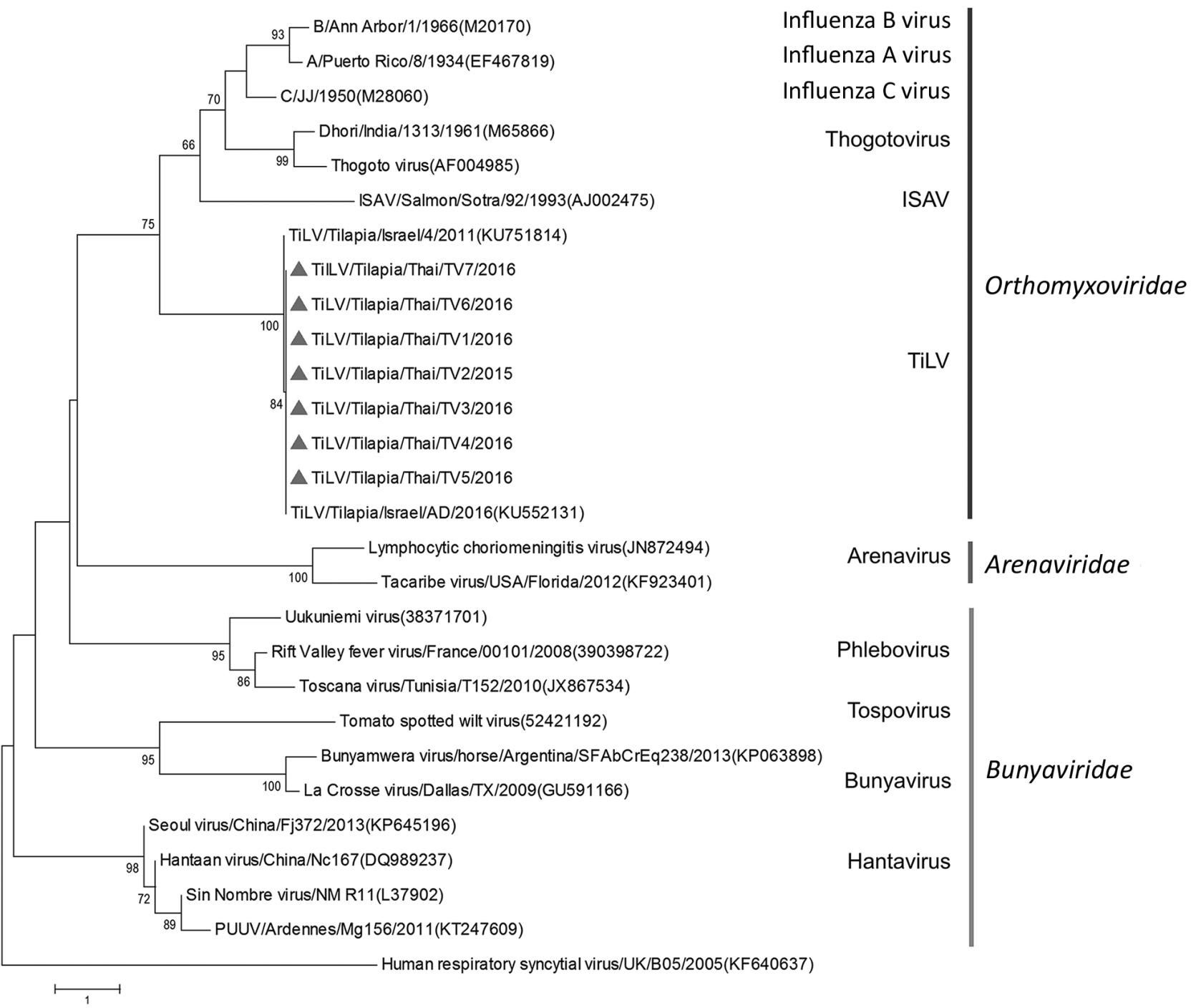

Figure. Phylogenetic analysis of the nucleotide sequences of RNA polymerase of TiLVs from Thailand (triangles) and reference viruses of the families Orthomyxoviridae, Arenaviridae, and Bunyaviridae. Genus and family groups are indicated; GenBank accession numbers are provided for reference viruses. The phylogenetic tree was constructed by using MEGA 6.0 (10) and applying a neighbor-joining bootstrap analysis (1,000 replications) with the Poisson model and gamma distribution. Human respiratory syncytial virus was used as an outgroup. ISAV, infectious salmon anemia virus; PUUV, Puumala virus; TiLV, tilapia lake virus. Scale bar indicates nucleotide substitutions per site.

tilapia in Israel and Ecuador $(4,7)$. Furthermore, the clinical signs and pathological presentation of infection with TiLV from Thailand are similar to those of infection with TiLV from Israel (online Technical Appendix Figure 2). The clinical signs, gross lesions, and histopathologic lesions combined with virus identification and characterization highlight emerging TiLV in Thailand as the primary cause of the outbreaks. We also found that fish that survived massive die-offs rarely showed clinical signs, suggesting the development of specific immunity against the virus. It should be noted that the TiLVs from Thailand possessed 10 gene segments encoding 10 proteins, including segment 1 or putative PB1 protein. The pattern of protein motifs for this putative PB1 was similar to that for influenza viruses. To our knowledge, TiLV has infected tilapia only, no other aquatic or terrestrial animals.

Our results emphasize that the virus isolated from Thailand shares high sequence similarity with TiLV from Israel, suggesting that this virus spreads across continents. Given that tilapia are the main aquaculture species, control of TiLV will be improved by further efforts such as strict biosecurity, vaccine development, and selection of resistant tilapia breeds. 


\section{Acknowledgments}

We thank the National Research Council of Thailand and the Agricultural Research Development Agency for financial support (PRP6005020450) and the Center for Advanced Studies for Agriculture and Food, Kasetsart University Institute for Advanced Studies. We also thank Chulalongkorn University for financial support to the Center of Excellence for Emerging and Re-emerging Infectious Diseases in Animals, the Thailand Research Fund for financial support to the Thailand Research Fund Senior Scholar (to A.A.) (RTA5780006), and the National Science and Technology Development Agency (P-15-50004).

Dr. Surachetpong is an assistant professor at the Faculty of Veterinary Medicine, Kasetsart University, Bangkok. His research interests are emerging viruses and immunology in aquatic animals.

\section{References}

1. Crane M, Hyatt A. Viruses of fish: an overview of significant pathogens. Viruses. 2011;3:2025-46. http://dx.doi.org/10.3390/ v3112025

2. Keawcharoen J, Techangamsuwan S, Ponpornpisit A, Lombardini ED, Patchimasiri T, Pirarat N. Genetic characterization of a betanodavirus isolated from a clinical disease outbreak in farm-raised tilapia Oreochromis niloticus (L.) in Thailand. J Fish Dis. 2015;38:49-54. http://dx.doi.org/10.1111/jfd.12200

3. Shlapobersky M, Sinyakov MS, Katzenellenbogen M, Sarid R, Don J, Avtalion RR. Viral encephalitis of tilapia larvae: primary characterization of a novel herpes-like virus. Virology. 2010;399:239-47. http://dx.doi.org/10.1016/j.virol.2010.01.001

4. Eyngor M, Zamostiano R, Kembou Tsofack JE, Berkowitz A, Bercovier H, Tinman S, et al. Identification of a novel RNA virus lethal to tilapia. J Clin Microbiol. 2014;52:4137-46. http://dx.doi.org/10.1128/JCM.00827-14

5. Ferguson HW, Kabuusu R, Beltran S, Reyes E, Lince JA, del Pozo J. Syncytial hepatitis of farmed tilapia, Oreochromis niloticus (L.): a case report. J Fish Dis. 2014;37:583-9. http://dx.doi.org/10.1111/jfd.12142

6. Kurita J, Nakajima K, Hirono I, Aoki T. Polymerase chain reaction (PCR) amplification of DNA of red seam bream iridovirus (RSIV). Fish Pathology. 1998;33:17-23. http://dx.doi.org/10.3147/ jsfp.33.17

7. Bacharach E, Mishra N, Briese T, Zody MC, Kembou Tsofack JE, Zamostiano R, et al. Characterization of a novel orthomyxo-like virus causing mass die-offs of tilapia. MBio. 2016;7:e00431-16. http://dx.doi.org/10.1128/mBio.00431-16

8. Müller R, Poch O, Delarue M, Bishop DH, Bouloy M. Rift Valley fever virus L segment: correction of the sequence and possible functional role of newly identified regions conserved in RNAdependent polymerases. J Gen Virol. 1994;75:1345-52. http://dx.doi.org/10.1099/0022-1317-75-6-1345

9. Poch O, Sauvaget I, Delarue M, Tordo N. Identification of four conserved motifs among the RNA-dependent polymerase encoding elements. EMBO J. 1989;8:3867-74.

10. Tamura K, Stecher G, Peterson D, Filipski A, Kumar S. MEGA6: Molecular Evolutionary Genetics Analysis version 6.0. Mol Biol Evol. 2013;30:2725-9. http://dx.doi.org/10.1093/molbev/mst197

Address for correspondence: Win Surachetpong, Faculty of Veterinary Medicine, Kasetsart University, Bangkok, Thailand 10900; email: fvetwsp@ku.ac.th

\section{Endemic Hantavirus in Field Voles, Northern England}

\author{
Anna G. Thomason, Michael Begon, \\ Janette E. Bradley, Steve Paterson, \\ Joseph A. Jackson
}

DOI: https://dx.doi.org/10.3201/eid2306.161607

Author affiliations: University of Salford, Salford, UK (A.G. Thomason, J.A. Jackson); University of Liverpool, Liverpool, UK (M. Begon, S. Paterson); University of Nottingham, Nottingham, UK (J.E. Bradley)

We report a PCR survey of hantavirus infection in an extensive field vole (Microtus agrestis) population present in the Kielder Forest, northern England. A Tatenale virus-like lineage was frequently detected $(\approx 17 \%$ prevalence) in liver tissue. Lineages genetically similar to Tatenale virus are likely to be endemic in northern England.

$\mathrm{R}_{\mathrm{r}}^{\mathrm{c}}$ ecently a new vole-associated hantavirus (Tatenale virus) was discovered in northern England (1), but only from an individual Microtus agrestis field vole. Previously only hantaviruses from murine-associated lineages (Seoul virus [SEOV] and SEOV-like viruses) had been reported in the United Kingdom, despite the abundance of potential vole hosts in the mainland United Kingdom and the endemicity of vole-associated hantavirus lineages (Puumala virus [PUUV] and Tula virus) in mainland Europe (2). Here we present data suggesting that the Tatenale virus lineage is endemic in northern England.

European hantaviruses are of public health significance because they are a causative agent of hemorrhagic fever with renal syndrome (HFRS). In the United Kingdom, HFRS cases have primarily been attributed to SEOV-like viruses on the basis of serologic tests. SEOV antibodies have been detected in both humans and Norway rats (Rattus norvegicus) in Northern Ireland and Yorkshire $(3,4)$, and seropositivity in humans correlates with domestic or occupational exposure to rats $(3,5)$. However, in the United Kingdom, HFRS cases with serologic cross-reactivity to PUUV (3), which might share antigenic determinants with Tatenale virus, have occurred.

To investigate the endemicity of hantavirus in field voles in the United Kingdom, we surveyed the extensive field vole population in the Kielder Forest, Northumberland $(\approx 230 \mathrm{~km}$ distant from the locality where Tatenale virus was discovered). All sampled sites were grassy, clear-cut areas (adjacent to forest stands) where field voles were prevalent. Fieldwork was approved by the University of Liverpool Animal Welfare Committee and conducted subject to UK home office project license PPL 70_8210. Following the 